\title{
Skin closure with Pfannenstiel incision in lower segment caesarean section; comparison of wound outcome with interrupted vs. subcuticular techniques
}

\author{
Dasanayake DLW ${ }^{1}$, Jodhi A K ${ }^{2}$, Roomadu KUGA ${ }^{2}$, Saumya GKR ${ }^{2}$ \\ ${ }^{1}$ Department of Obstetrics \& Gynaecology, Faculty of Medicine, University of Ruhuna, Galle, Sri Lanka. \\ ${ }^{2}$ Department of Nursing, Faculty of Natural Sciences, Open University of Sri Lanka..
}

Correspondence: Dr. DLW Dasanayake

e-mail: lanka.dasanayake@yahoo.com

(1) https://orcid.org/0000-0003-4330-9641

\begin{abstract}
Introduction: Caesarean section is the most common surgical procedure performed in the world. A vast majority of the procedures are carried out with Pfannenstiel incision. Different techniques and materials are used to approximate the skin in caesarean section. Each method has its own advantages and disadvantages. The objective of the study was to compare surgical wound outcome and satisfaction of women who underwent Pfannenstiel incision closure with interrupted vs. subcuticular suturing in caesarean sections.

Methods: A prospective comparison was carried out in 400 age and body mass index matched women who underwent lower segment caesarean section for the first time. Standard lower segment caesarean section was performed with assigning interrupted and subcuticular wound closure for 200 women in each group, following matching for BMI and age. Two arms were compared for wound complications, postoperative pain and overall satisfaction of the outcome.

Results: There was no statistically significant difference between groups for baseline characteristics (age, BMI and category of caesarean sections). According to visual analogue scale $91 \%$ of women reported to have moderate to severe pain in interrupted group compared to $80 \%$ in subcuticular group $(\mathrm{p}<0.05)$. Wound complications were present in $8 \%$ of interrupted group vs $3 \%$ in subcuticular group $(p<0.001)$. Sixty four percent of women were satisfied with subcuticular method vs. $28 \%$ with interrupted method $(p<0.001)$.

Conclusions: Women who had subcuticular suturing method had less post-operative pain, better wound outcome and more satisfaction compared to interrupted suturing.
\end{abstract}

Keywords: Caesarean section, Pfannenstiel incision, wound closure, wound outcomes

\section{Introduction}

Caesarean section is one of the most common surgical procedures performed worldwide. It was first described and performed by Hermann Pfannenstiel in 1900 (1). This involves low transverse suprapubic incision with the dissection of rectus muscles from the overlying rectus sheath. This has become popular and currently is the incision of choice in most of the obstetric and gynaecological surgeries. Currently a vast majority of caesarean sections are being performed using this incision $(2,3)$.

Advantages of this skin incision over a vertical incision are; low rate of complications (infection, haematoma and gaping) and rapid healing with cosmetically better appearance. This results in closing dead space, supporting and strengthening wound until healing is completed and approximating 
skin edges for the aesthetic results minimizing bleeding and risk of infection (4). Skin union can be observed by $48 \mathrm{hrs}$ of the surgery and complete union take place by the seventh post-operative day. Surgical closure also serves functional and aesthetic purposes, for example, the elimination of dead space by approximating the subcutaneous tissues; careful epidermal alignment resulting in minimisation of scar formation; and avoidance of a depressed scar by precise eversion of skin edges (5).

There are several techniques to close the skin; interrupted mattress, subcuticular adhesive types and staplers. Each technique has its own advantages and disadvantages. The subcuticular technique involves running a stitch through subcuticular or epidermal tissue. This is an easy method of approximation of skin. Interrupted vertical mattress stitch involves piercing the skin at four points at the same level for a single stitch with a good amount of subcuticular tissue and fat. This closure allows blood and serosanguinous tissues to drain. However, this technique is time consuming (6).

Caesarean section has no universally agreed standards on operative techniques or materials to use. There is no conclusive evidence about how the skin should be closed after caesarean section. Questions regarding the best closure techniques and outcome are remaining unanswered. Post-operative wound related complications and scar related morbidity following caesarean section is important to women for the optimal obstetric care. There is no conclusive evidence to say whether any particular technique for closing abdominal wound in caesarean section is better than the other.

In the current context due to limitations of the evidence particularly of skin closure, obstetricians use different closing techniques to approximate the skin during caesarean section. The aim of the study was to compare wound outcome and maternal satisfaction in subcuticular and interrupted techniques for skin closure in caesarean section.

\section{Methods}

The study was carried out in selected 400 women who had caesarean delivery with Pfannenstiel incision for the first time in a single obstetrics unit. There were three age categories $(<25$ years, $26-35$ years and >35 years) and four BMI categories (underweight, average, overweight and obese). It was make sure to allocate approximately similar number of mothers consecutively for each category while assigning woman for two methods of suturing to get 200 mothers in each group for the prospective assessment of the outcome. Interviewer administrated questionnaire was used for the data collection. The questionnaire consisted of three sections. Section one was related to demographic data, section two contained data on wound related complications and last section was on patient satisfaction. Data collection was done at postoperative day 1 , day 3 and day 14 . Women were advised to seek immediate medical advice if there were any wound related complications during follow up period.

Women with diabetes, multiple pregnancies and maternal medical problems were excluded from the study. All caesarean sections had been performed by trained middle grade medical officers under the supervision of the obstetrician without giving any preference to either of the techniques. Group 1 consisted of women with subcuticular suturing for incision closure with absorbable material (No. 3.0 polyglecaprone and group 2 consisted of women with interrupted suture with non-absorbable material (No. 0 Nylon). Perioperative antibiotics had been given prior to the procedure in all cases. Routine skin cleaning was done with povidone iodine and ethyl alcohol. Skin incision was performed with Joel-Cohen incision. Rest of the caesarean section was done in the standard way. On the post-operative day 3 , the two groups of women were asked to indicate the level of post-operative pain using a visual analogue scale. The dressing was open on the third day and wound was inspected for any complications. Uncomplicated patients were discharged on post-operative day 3 and women in group 2 were advised to have suture removal on day 7. After two weeks of the surgery, mothers were assessed for wound related complications and their overall satisfaction was assessed using 1 to 5 satisfaction score. Categorical variable of satisfaction was ranging from not satisfied to highly satisfied.

Ethical approval was obtained from Ethical Review Committee, Faculty of Medicine, University of Ruhuna. Informed written consent was obtained 
from all participants. Data were stored in password protected database and were analysed for the statistical significance by chi-square test for qualitative data and t-test for quantitative data.

\section{Results}

Table 1 summarizes baseline characteristics of the study groups. There were 400 women recruited for the study with 200 in each group. Approximately two third of women belong to age category of 26-35 years in both study groups. Approximately $40 \%$ of women in both groups were within the normal range for BMI. More than $90 \%$ of women were Sinhala Buddhists. Half of the women in both groups had studied up to A/L. In both groups almost half of women underwent elective caesarean sections. There was no statistically significant difference in study groups with regards to baseline characteristics.
Table 2 summarizes outcome of different suture techniques. In both groups, a vast majority of women experienced moderate to severe pain and it was significant in women with interrupted suture technique compared to subcuticular technique $(91.5 \%$ vs. $80.5 \%, \quad(p<0.05)$. Overall wound complications were observed more in interrupted group than in the subcuticular group $(8 \%$ vs. $3 \%$, $(\mathrm{p}<0.001)$. There was a clinically significant difference in wound complications in interrupted group than in subcuticular group. There was a statistically significant difference of overall satisfaction with $64.5 \%$ of women in subcuticular group vs. $28 \%$ in interrupted group $(\mathrm{p}<0.001)$.

Table 1: Socio-Demographic characteristics of the participants $(n=400)$

\begin{tabular}{llrcccr}
\hline \multirow{2}{*}{$\begin{array}{l}\text { Demographic } \\
\text { Characteristics }\end{array}$} & Category & $\begin{array}{c}\text { Frequency } \\
\text { (n=200) }\end{array}$ & $\begin{array}{c}\text { Percentage } \\
(\boldsymbol{\%})\end{array}$ & $\begin{array}{c}\text { Frequency } \\
(\mathbf{n = 2 0 0})\end{array}$ & $\begin{array}{c}\text { Percentage } \\
(\mathbf{\%})\end{array}$ & p value \\
\hline Age (years) & $\leq 25$ & 37 & 18.5 & 40 & 20 & 0.92 \\
& $26-35$ & 138 & 69 & 135 & 67.5 & \\
& $>35$ & 25 & 12.5 & 25 & 12.5 & \\
\hline BMI & Under wt. & 42 & 21 & 40 & 20 & 0.35 \\
& Normal & 84 & 42 & 88 & 44 & \\
& Over wt. & 39 & 19.5 & 31 & 15.5 & \\
& Obese & 35 & 17.5 & 41 & 20.5 & \\
\hline Race & Sinhalese & 186 & 93 & 184 & 92 & 0.7 \\
& Other & 14 & 7 & 16 & 8 & \\
\hline Religion & Buddhist & 185 & 92.5 & 184 & 92 & 0.85 \\
& Other & 15 & 7.5 & 16 & 8 & \\
\hline Educational & $\leq$ O/L & 119 & 59.5 & 102 & 51 & 0.09 \\
level & $\geq$ A/L & 81 & 40.5 & 98 & 49 & \\
\hline Category of & Emergency & 88 & 44 & 97 & 48.5 & 0.37 \\
LSCS & Elective & 112 & 56 & 103 & 51.5 & \\
\hline
\end{tabular}


Table 2: Outcome of different suture techniques

\begin{tabular}{llccccc}
\hline \multirow{2}{*}{$\begin{array}{l}\text { Outcome } \\
\text { variables }\end{array}$} & Categories & $\begin{array}{c}\text { Subcuticular } \\
\text { Frequency } \\
(\mathbf{n = 2 0 0})\end{array}$ & $\begin{array}{c}\text { Percentage } \\
(\boldsymbol{\%})\end{array}$ & $\begin{array}{c}\text { Frequency } \\
(\mathbf{n = 2 0 0})\end{array}$ & $\begin{array}{c}\text { Percentage } \\
(\boldsymbol{\%})\end{array}$ & p value \\
\hline Pain (visual & $<5$ (mild) & 39 & 19.5 & 17 & 8.5 & $<0.05$ \\
analogue scale) & $>5$ (moderate & 161 & 80.5 & 183 & 91.5 & \\
& to severe) & 6 & 3 & 16 & 8 & $<0.001$ \\
\hline Overall wound & Present & 194 & 97 & 184 & 92 & \\
complications & Not present & 3 & 1.5 & 4 & 2 & - \\
\hline Different types & Seroma & 1 & 0.5 & 3 & 1.5 & \\
of Wound & Hematoma & 4 & 2 & 9 & 4.5 & \\
complications & Gaping & 192 & 96 & 184 & 92 & $<0.001$ \\
\hline Overall & None & 129 & 64.5 & 56 & 28 & \\
Satisfaction & Satisfied & 71 & 35.5 & 144 & 72 & \\
& Not satisfied & & & & & \\
\hline
\end{tabular}

\section{Discussion}

Current study showed that women who had subcuticular suturing technique had less postoperative pain, better wound outcome and more satisfaction compared to interrupted suture technique.

As caesarean section is the most common surgical procedure performed worldwide, incision related morbidity is of paramount importance for the overall improvement of maternity care. Out of other modalities of deliveries, caesarean section related pain is worse. Skin closure significantly contributes for the severity of pain. In this study, subcuticular group had less pain score than interrupted group. This may be due to involvement of more tissue bulk with tightening in the interrupted suturing technique.

Approximately $10 \%$ of women suffered from wound related morbidity, mostly due to approximation of the skin. Our study found that occurrence of wound complications in interrupted group more than in the subcuticular group. Choudhary A, et al. has reported that subcuticular absorbable material offered better skin approximation and healing than interrupted suture which needed re-suturing more often (7). Makeen, et al. in their systematic review of Cochrane database on techniques and material for closure of caesarean section found that non absorbable staples were associated with increased risk of separation and resuturing than absorbable subcuticular suturing (6).

In randomized controlled trials performed by Brown $\mathrm{JK}$, et al. they compared subcuticular absorbable suturing to skin adhesives. They had observed that there was no difference in cosmetic outcome in skin closure provided adhesive skin approximation for proper healing. Skin adhesives on the other hand are more expensive than suturing though it reduces operating time (8).

It was found that subcuticular suture is not only cost effective but also saves operating time when compared to interrupted mattress. A study done by Choudhary A, et al. in 2017 revealed that subcuticular absorbable suture is superior to interrupted mattress when wound outcome is considered. Time taken for skin closure was less and approximation was better without tension. Women were discharged earlier since there was no need for suture removal (7).

Guruswami, et al. in their systematic review in Cochrane database compared continuous vs. interrupted mattress for non obstetric surgeries found that superficial wound adhesions may be reduced by using subcutaneous continuous sutures. This observation is in agreement with our findings of 
lesser incidence of wound gapping with subcuticular techniques (9).

This study also shows that women's satisfaction score was much higher in subcuticular group than interrupted group. This reflects overall less postoperative pain and minimal wound related morbidity in subcuticular group than interrupted group. Similar finding was reported by Aliya I, et al. in 2011(10).

\section{Limitations}

There are some limitations of this study. We have considered the BMI of these patients but not the other parameters such as skin thickness and variability of the thickness of abdominal fat layer which could have influenced the wound outcome more than the BMI. Further, the sections were performed by different medical officers under the supervision of an obstetrician rather than a single surgeon performing the technique in all patients.

\section{References}

1. Wylie BJ, Gilbert S, Landon MB, Spong CY, Rouse DJ, Leveno KJ, et al. A comparison of transverse and vertical skin incision for emergency cesarean delivery. Obstet Gynecol. 2010; 115(6): 1134-40.

2. Figueroa D, Jauk VC, Szychowski JM, Garner R, Biggio JR, Andrews Wet al. Surgical staples compared with subcuticular suture for skin closure after cesarean delivery: a randomized controlled trial. Obstet Gynecol, 2013; 121(1):33-8.
3. Altman AD, Allen VM, McNeil SA, Dempster J. Pfannenstiel incision closure: a review of current skin closure techniques. J Obstet Gynecol Canada. 2009; 31(6): 514-20.

4 Walter JB, Israe IMS. Wound healing, Textbook of General Pathology, $6^{\text {th }}$ ed. Ch.9: 124-5.

5. Vuolo, Julie Caroline. Assessment and management of surgical wounds in clinical practice. Nursing Standard, 2006; 20(52): 46-52. Gale Academic OneFile, Accessed 16 Sept. 2019.

6. Mackeen AD, Berghella V, Larsen ML, Techniques and materials for skin closure in caesarean section. Cochrane Database Syst Rev, 2012; 11: Cd003577.

7. Choudhary A, Bansal N, Chaudhari P. Closure of Pfannenstiel skin incisions in cesarean sections: comparison of wound outcomes with interrupted mattress vs. subcuticular suture. Int J Reprod Contracept Obstet Gynecol, 2017; 6: 2964-8.

8. Brown JK, Campbell BT, Dronogowski RA, Alderman AK, Giger JD, Teitlbaum DH, et al. A prospective, randomized comparison of skin adhesive and subcuticular suture for closure of pediatric hernia incisions: cost and cosmetic considerations. J Pediatr Surg, 2009; 44(7): 1418-22.

9. Guruswamy KS, Toon CD, Allen VB, Davidson BR. Continuous versus interrupted sutures for non-obstetric surgery. Cochrane Database Syst Rev, 201414 February Cd010365.

10. Aliya I, Amdreen E. Comparison of suture material and technique of closure of subcutaneous fat and skin in caesarean section. NAm J Med Sci, 2011 Feb; 3(2): 85-88. 